\title{
GOUDEXPLOITATIE IN SURINAME
}

DoOR

\section{JUNKER}

\section{Algemeene beschouwingen}

Vóór ongeveer zestig jaren werden in Suriname de eerste belangrijke goudvondsten, die tot ontginning hebben geleid, gedaan. De ervaring, in dien tijd opgedaan, leert, dat het goud in den Surinaamschen bodem grillig verspreid voorkomt. Prospecties hebben uitgewezen, dat op sommige plaatsen het goud, aan gesteenten gebonden, in belangrijke hoeveelheden voorkomt. In andere terreinen weer werden goede depositos in diluviale formaties gevonden. Dit laatste vindt in het bijzonder in de nabijheid van kreeken plaats. Oude, onder den grond bedolven, afwateringen van deze kreeken hebben dikwijls aanzienlijke hoeveelheden goud opgeleverd.

De gouddelvers verdeelen de oppervlakte van Suriname in drie, van Oost naar West nagenoeg evenwijdig verloopende, goudzônen. In de eerste en tweede zône heeft zich de goudindustrie ontwikkeld, zooals deze tegenwoordig aangetroffen wordt. Daar, waar grootere ophoopingen van goud werden aangetroffen, verrezen machinale bedrijven. De hooge verwachtingen echter, die men na de eerste vondsten koesterde, werden niet verwezenlijkt; de machinale bedrijven hebben tot groote teleurstellingen geleid. In veel gevallen waren deze verwachtingen op bedriegelijke opgaven van prospecties gegrond en heeft de terbeschikkingstelling van kapitaal voor deze ondernemingen geheel en al op zwendel berust. Die heeft de Kolonie veel schade berokkend, veel er toe bijgedragen, dat men tegenover kapitaalsbelegging in Suriname met wantrouwen staat. Niettemin hebben vroegere besturen het optimisme ten opzichte van de goudindustrie in hooge mate gedeeld en daarop de wetgeving gebouwd. Het van regeeringswege ingesteld onderzoek, de zoogenaamde Lawa-exploratie, heeft duidelijk aangetoond, dat de inzichten, welke ten opzichte van de goudindustrie toen in bestuurskringen heerschten, onjuist waren. Reeds tevoren had de 
debacle van Granplacer, de onderneming der maatschappij Suriname, aan welke de aanleg van den spoorweg was gekoppeld, het bestuur van Suriname de oogen kunnen openen.

$\mathrm{Na}$ afloop der Lawa-exploratie, die ongeveer drie jaren in beslag heeft genomen, publiceerde Ir. Middelberg, de leider van dit onderzoek, zijn technische en geologische aanteekeningen. Hierin wordt gezegd, dat de goudhoudende beddingen weinig uitgestrekt zijn en aan stabiele, machinale bedrijven geen kansen bieden. Wel acht de heer Middelberg het mogelijk de productie van goud door vele kleine groepen gouddelvers, die over de goudvoerende formaties verspreid werken, hooger op te voeren.

Het moet daarom ook een verkeerde politiek genoemd worden het oprichten van dergelijke bedrijven in de hand te werken en te hunnen bate eene, door de werkelijkheid ondoelmatige, wetgeving te handhaven.

Ten allen tijde hebben zich de bestuurders van Suriname weinig aan de adviezen van deskundigen gestoord. Ten aanzien van den landbouw zijn in het rapport van het Suriname Studie Syndicaat waardevolle adviezen vervat; deze worden echter, precies als de raadgevingen van den heer Middelberg, genegeerd. De nu heerschende toestand werd in een artikel, dat onder de rubriek „de Wereldpers" in de Haagsche Post uit een Engelsch tijdschrift was overgenomen, treffend wedergegeven. Onder het hoofd „Koloniaal Probleem” hebben wij kunnen lezen: „Een moeilijkheid bij het koloniseeren wordt gevormd door den bestuurder, die, zelfs als hij het kan verkrijgen, geen advies van specialisten wil aanvaarden, omdat hij denkt, dat hij het daarvoor te druk heeft, of gelooft, dat hij het zelf wel weet, of het pijnlijk vermoeden heeft, dat hij het niet weet en daarom geen advies kan verdragen, zelfs niet over de meest technische aangelegenheden, van menschen, die, zij het ook op de meest tactvolle wijze, dit vermoeden wellicht zouden bevestigen." Hier kan aan toegevoegd worden, dat een bestuurder, die geen zelfstandige meening heeft, in den regel alles aan de beoordeeling van zijn departementshoofden overlaat. Hierdoor wordt de toestand nog ongewenschter, onderlinge naijver komt in het spel en de hoogst hoodige samenwerking in een kleine koloniale huishouding raakt daarbij meestal zoek, hetgeen op geheele bestuursperioden een noodlottigen invloed kan uitoefenen.

$\mathrm{Na}$ deze afdwaling komen wij op het eigenlijke onderwerp, de goudexploitatie in Suriname, terug. In de eerste plaats zullen wij het over de ontwikkelingsmogelijkheden hebben. Hierbij wordt de 
lijn gevolgd, die de heer Middelberg heeft aangegeven. Alvorens echter hiertoe over te gaan zullen wij terwille van het goed begrip van de aangelegenheid eerst nog de vraag stellen wat had het bestuur, dat in het bezit van het advies van den Ir. Middelberg werd gesteld, moeten doen. Het antwoord zal moeten luiden, dat twee mogelijkheden van uitvoering bestonden:

$a$. te beletten, dat op voorspiegelingen van groote, in de Kolonie aanwezige, goudvoorraden verder kapitaal op bedriegelijke wijze in Suriname werd belegd;

$b$. te bevorderen, dat de ontginning van kleine ondernemers op groote schaal werd ter hand genomen.

Het onder $a$ vermelde is niet geschied. Het tegendeel heeft plaats gehad.

$\mathrm{Na}$ het uitbrengen van het advies door den leider der Lawaexploratie in het jaar 1908 werden nog steeds concessies voor machinale bedrijven uitgegeven. Nog in 1912 installeerde eene Engelsche maatschappij met de penningen van kleine spaarders een groote baggermolen, die kort na het in gebruik nemen wegens armoede aan goud van den grond zijn werk moest staken. Ook de gedurende de laatste jaren wederom in het leven geroepen machinale bedrijven hebben reeds tot teleurstellingen geleid.

Wat het onder $b$ bepaalde aangaat moet vermeld worden, dat de op bekrompen wijze in 1912 getroffen maatregel van een gouvernementskleinbedrijf kan beschouwd worden als eene proef, die voorbestemd is geweest een negatief resultaat op te leveren. Het bedrijf werd immers opgezet op een terrein, dat tevoren reeds gedurende bijna veertig jaren door gouddelvers was afgeloopen.

\section{Wettelijke bepalingen}

Het goudbedrijf in Suriname wordt wettelijk geregeld door twee verordeningen, te vinden in G.B. 1905 nos. 1 en 2. In G.B. 1905 no. 1 zijn de bepalingen omtrent het onderzoek naar goud opgenomen, terwijl in G.B, 1905 no. 2 de ontginning behandeld wordt. De eerste afdeeling van G.B. no. 1 werd in 1931 in dier voege gewijzigd, dat onderzoek en ontginning door elkander geworpen werden, waardoor in de wetgeving eene tegenstrijdigheid ingeslopen is. Omtrent het ontstaan van deze wijziging lezen wij in het avondblad van den N.R.C. van 23 Mei 1933 het volgende:

„In 1931 deed het te Paramaribo opgehoopt proletariaat zijn stem in de aangelegenheid der goudontginning als werkverschaffinghooren. In geen ander land ter wereld zal dit vraagstuk inderdaad zoo gemakkelijk opgelost kunnen worden als in Suriname. 
Duizende voor het bosch getrainde werkloozen loopen te Paramaribo rond en uitgestrekte goudhoudende terreinen bieden de gelegenheid aan, een goed stuk brood te verdienen. Het is daarom te betreuren, dat in 1931 geen zakenman of een man met een ruimen blik als beheerder der domeinen adviseur van den Gouverneur is geweest. Instede van tot een studie der omstandigheden met het oog op de goudontginning over te gaan werd (gemakshalve) de goudverordening door een burokratischen maatregel gewijzigd. Aan de werkeloozen werd vrij onderzoek in honderden malen afgeloopen terrein toegestaan. Het resultaat is dan ook volkomen in overeenstemming met den maatregel geweest. Uit de officieele bekendmaking blijkt, dat aan de Surinamerivier gedurende 1932 door 34 groepen gouddelvers slechts 5844 grammen goud werden geproduceerd. Dat is 43 gram per persoon."

Voor deze opbrengst heeft het bestuur voor uitrusting en verzorging der gouddelvers het driedubbele besteed van hetgeen deze hoeveelheid goud bij verkoop kon opbrengen. Deze episode uit de wetgeving voor het goudbedrijf toont duidelijk aan hoe het met het inzicht in het algemeen gesteld is. Gebrek aan kennis van de werkelijkheid en minachting van het juist inzicht van anderen hebben reeds aan de wieg der verordening gestaan. De droom van een Eldorado stond op den voorgrond. De optimisten van destijds zagen een goudrush in het verschiet, en wilden bijtijds de maatregelen treffen om den stroom des overvloeds in de rustige bedding van een gezonde wetgeving te geleiden. Het zakelijk inzicht hiervan zoude niet betwist kunnen worden, wanneer men zich tevoren van de werkelijkheid had overtuigd. Onderzoek hiernaar heeft eerst plaats gehad na de invoering der verordening. Hierbij moet men niet vergeten, dat de voornaamste bedoeling der wetgeving op het goudbedrijf was geweest aan het buitenlandsche kapitaal te toonen, dat in Suriname onder wettelijk geregelde toestanden zaken konden worden gedaan. Hoe dit gelukt is en hoe de machinale bedrijven mislukt zijn werd reeds vermeld.

De slechte, bij deze bedrijven opgedane, ervaringen hebben echter niet geleid tot eene wijziging van de wet, waarbij rekening werd gehouden met de ontwikkeling van een klein bedrijf, zooals dit door den heer Middelberg bedoeld werd. De goudverordening, die direct tegen het kleinbedrijf gericht is, bleef gehandhaafd en vormt zoodoende een hinderpaal voor de economische en sociale ontwikkeling der Kolonie. Teneinde zich een goed begrip van deze aangelegenheid te kunnen vormen moet men met de toestanden, die hierna besproken worden, bekend zijn. 
Het gouddelven vereischt kapitaal; voor den kleinen ondernemer is althans het voor hem hooge bedrag van vijf à zes honderd guldens met de onderneming gemoeid. Omdat men meestal niet over deze som beschikt, verleent een geldschieter uitkomst. Dit beteekent hooge rente, en vele gouddelvers zijn niet in staat daaraan te ontkomen. Zoo is het bijna altijd bij het goudkleinbedrijf geweest. Het voorbereidende stadium der goudontginning is het onderzoek, de nadere prospectie van goudvoerende formaties, welke goede aanwijzingen hebben vertoond. De goudzoeker moet beginnen den landmeter voor het vervaardigen der kaarten, die bij de door de wet geëischte aanvrage moeten gevoegd worden, te betalen. Verder zijn nog zegels en leges voor de aanvraag verschuldigd. Wordt het verzoek om naar goud te mogen zoeken ingewilligd, dan moeten de rechten ad een cent per hectare en per jaar, vooruitbetaald worden. Vervolgens moet de ondernemer in overeenstemming met de bepalingen der Arbeidsverordening met de arbeiders voor den duur der prospectie overeenstemmen. Ook hier komt de fiscus bij te pas. Tenslotte moet de ondernemer het vervoer naar de plaats van bestemming betalen en ervoor zorg dragen, dat er voor eenige maanden kost is en den arbeiders hun dagloon betaald wordt.

Is de goudzoeker gedurende de prospectie gelukkig geweest en wettigen de aanwijzingen het overgaan tot ontginning, dan wordt door hem de oppervlakte opgegeven, van de plaats waar bij het onderzoek goud werd gevonden. In den regel worden bij de aanvraag om concessie tot exploitatie 200 hectaren van de soms duizenden hectaren groote oppervlakte, die voor onderzoek was uitgegeven, aangevraagd. Ofschoon van de betrekkelijke kleine oppervlakte, die in concessie uitgegeven wordt, door een beëedigd landmeter eene figuratieve kaart vervaardigd wordt, bestaat voor den ondernemer niet de minste rechtszekerheid. Alle uitgiften van land in het binnenland van Suriname zijn, met uitzondering van oppervlakten, die door uitmeting zijn vastgelegd, op vermoedelijk aanwezige toestanden gefundeerd. Een voorval, dat zich twintig jaren geleden voordeed, teekent dezen toestand het best. Ten behoeve van de balataverordening was door het domeinkantoor eene blokkaart van Suriname geteekent, naar welke de concessies werden uitgegeven. Blokperceel IX van deze kaart was onderverdeeld in perceelen van 5000 hectaren. Deze werden ten behoeve van het kleinbedrijf uitgegeven. Grensverschillen veroorzaakten, dat tot een gedeeltelijke uitmeting moest worden overgegaan, en daarbij bleek, dat het perceel 0 in het geheel niet bestond. Bij het 
teekenen der kaart had men rekening gehouden met den vermoedelijken loop der Commewijnekreek, zooals deze in de officieele kaart van Suriname, die voor het uitgeven van concessies gebruikt wordt, voorkwam.

Daar zulks plaats kon hebben ten aanzien van eene oppervlakte van 5000 hectaren, zal het begrijpelijk zijn dat de eigen opgave van een gouddelver van een plek, groot 200 hectaren, ergens in het land, geen waarde kan hebben. Deze opgaven echter, die op de ten domeinkantore te Paramaribo aanwezige officieele kaart worden ingeteekend, vormen het uitgangspunt voor vervolging, wanneer de houder van eene concessie geacht wordt in overtreding te zijn door buiten de imaginaire grens van zijn geheel en al op vermoeden uitgegeven land goud te ontginnen. Volgens de strafbepaling, opgenomen in art. 36 der verordening, kan de overtreder met een gevangenisstraf van ten hoogste vijf jaren gestraft worden.

De onkosten, die voor het onderzoek moeten gemaakt worden, worden bij het begin der ontginning verhoogd door de rechten van het in exploitatie te nemen land. Dit recht bedraagt voor de eerste twee jaren tien cent per hectare en per jaar, voor de volgende twee jaren vijf en twintig en voor ieder verder jaar vijftig centen, en moet ieder jaar vooruitbetaald worden. Buitendien heft het gouvernement voor ieder gewonnen gram goud vier centen. Op onregelmatigheden bij het tot in bijzonderheden geregeld vervoer van goud staan zware straffen.

\section{De toestand elders in de Guyanas}

Zoowel in Engelsch als ook in Fransch Guyana is de toestand geheel anders dan in Suriname. In Demerara is het onderzoek naar goud vrij en bestaat ten opzichte van de ontginning het zoogenaamde claim-system. Een gouddelver, die een opslagplaats van goud ontdekt heeft, laat de vindplaats door een boschopzichter in het terrein vastleggen. Door deze officieele handeling wordt de afgepaalde plek de onaantastbare werkplaats van den vinder.

In Cayenne is zoowel het onderzoek als ook de ontginning geheel vrij. Tengevolge hiervan heeft zich het goudbedrijf in de Fransche kolonie geheel anders ontwikkeld dan in Suriname. In het binnenland worden daar in tegenstelling met Suriname overal vestigingen van Creolen aangetroffen. Franschen van de eilanden St. Lucia en Martinique hebben kleine aanplantingen van suikerriet, cassaven, bananen en groenten, anderen weer houden er daarbij winkels op na; in magazijnen, die op warenhuizen gelijken, kan men van alles koopen: conserven, modeartikelen, gereedschap- 
pen, alle dranken; zelfs Hollandsch bier ontbreekt niet. De betaling heeft voornamelijk in goud plaats; de winkeliers en houders van magazijnen zijn nl. tevens goudopkoopers. In deze samenleving - aan een groote kreek, de Inini, zijn geheele dorpen van gouddelvers - ontstaan hoort men zelden van ongeregeldheden. Van moord en doodslag, die door de Hollandsche autoriteiten werden gevreesd, wanneer nu en dan de vrije exploitatie van goud in Suriname ter sprake werd gebracht, hoort men zoo goed als nooit. De tegenstanders van een betere wetgeving ten behoeve van de goudindustrie in onze Kolonie zullen toch moeten toegeven, dat het uitbuiten van kleine spaarders ten behoeve der machinale goudbedrijven moreel niet hooger staat dan de opvattingen van recht in deze vrije samenlevingen. Men zoude echter te ver gaan, wanneer men de in Cayenne heerschende toestanden voor Suriname als voorbeeld ging stellen. In hun wezen vertegenwoordigen beide wijzen van ontginning uitersten, hier ongebondenheid en daar ondoelmatige gebondenheid.

Het ligt in mijn bedoeling den gulden middenweg aan te wijzen, die mij door mijn nauwe aanraking gedurende vele jaren met de zwoegers in het oerwoud is duidelijk geworden. Vooral moet echter de economische ontwikkeling van Suriname op den voorgrond staan. Ik wil trachten een bijdrage te leveren tot gedeeltelijke oplossing van het sociale vraagstuk der werkloosheid in Suriname en tevens het Nederlandsche kapitaal aan te moedigen op een reëele basis in Suriname gelden te investeeren.

\section{Wijze van goud ontginnen in Suriname}

Met het oog op de werkelijke toestanden, die den doorslag voor de technische uitvoering geven, en de gegeven omstandigheden op economisch en sociaal gebied is de reorganisatie en de uitbouw der goudindustire in Suriname slechts mogelijk, wanneer de meening van Ir. Middelberg tot richtsnoer wordt genomen. Omdat verwacht kan worden, dat door would-be deskundigen op het gebied van Surinaamsche aangelegenheden stelling tegen de in dit artikel geuite denkbeelden zal worden genomen, is het noodig te vermelden, dat reeds in het jaar 1933 in de N.R.C. eenige artikelen zijn verschenen, waarin het goudontginnen als werkverschaffing is behandeld. Toen heeft een oud-hoofdambtenaar van Suriname getracht de onjuistheid van de in die artikelen weergegeven toestanden aan te toonen. Het is hem niet gelukt; integendeel, zijne onbekendheid met de werkelijke toestanden is duidelijk geworden Ik vermeld dit slechts, daar, zooals reeds gezegd is, tegenwerking 
van invloedrijke personen, die een prestige te verdedigen hebben verwacht kan worden.

In de hiervoren genoemde artikelen wordt verwezen naar de ervaringen, die men in Suriname bij de balata-industrie heeft opgedaan. Deze goed georganiseerde industrie, wier voornaamste vertegenwoordigster de Rotterdamsche „Balata Companie Suriname" is geweest, had de geheele oppervlakte der Kolonie in beslag genomen. Over groote gebieden verspreid, verzamelden kleine groepen arbeiders het product. Andere groote gebieden werden door groots opgezette prospectie onderzocht. Ambtenaren van het gouvernement controleerden de werdzaamheden, talrijke rapporten omtrent de toestanden in het achterland, zoowel de balataen de goudindustrie als den houtaankap rakende, werden ingediend. Ook voorstellen tot het vestigen van gouddelvers naar het voorbeeld van Caypnne, doch onder beter geregelde omstandigheden en wettelijk toezicht, werden gedaan. Aan niets heeft de ambtenarij te Paramaribo aandacht besteed, de vergunningen van het reusachtigc achterland hebben geen enkel werkplan voor de toekomst kunnen uitlokken. Met het ophouden der balata-industrie, door het verdwijnen der afzetmogelijkheid van het product op den wereldmarkt, is het Surinaamsche binnenland weder tot zijn geheimzinnige verlatenheid teruggekeerd.

Alvorens wij tenslotte aan het denkbeeld, welks verwezenlijking tot den uitbouw der goudindustrie in Suriname zal kunnen leiden, een meer concreten vorm geven, zal ten behoeve van de vorming van een goed begrip van het te ontvouwen plan een korte beschrijving van de organisatie van het balatabedrijf gegeven worden. Zooals hiervoor reeds vermeld werd, had de exploitatie van de tevoren verkende bosschen plaats door middel van talrijke, verspreide groepen bleeders, zooals die arbeiders genoemd werden. Iedere groep, zelden meer dan zes arbeiders sterk, zocht aan een kreek een geschikte plaats voor het oprichten van eene drogerij uit. De verschillende werkplaatsen in een bepaald terrein waren aangesloten aan een centraal magazijn; van hier uit werden levensmiddelen en andere benoodigdheden gedistribueerd. Hierheen werd ook het product vervoerd. Een ter plaatse aanwezige opzichter was met het toezicht op het terrein belast en droeg zorg over de aan het bedrijf verbonden administratieve werkzaamheden. $\mathrm{Na}$ het eindigen der campagne hadden de verrekeningen op de kantoren te Paramaribo plaats.

De bedrijfskosten waren betrekkelijk gering. Dure machines en een uitgebreide staf van technisch personeel waren overbodig. 
Slechts de aanleg en het onderhoud van opslagplaatsen en de voor de contrôle en de afvoer noodige booten brachten grootere uitgaven met zich mede. De magazijnen werkten als winkelbedrijven met hooge winsten en dekten voor een groot deel de onkosten van het geheele bedrijf. De Balata Compagnie Suriname heeft dan ook steeds winsten gebracht; bij liquidatie der onderneming konden de aandeelen ten volle terug betaald worden.

De geschiedenis der balata-industrie toont aan, dat bij goede organisatie en behoorlijk samenwerken van alle voor de ontwikkeling van het bedrijf gunstige factoren in Suriname, in tegenstelling tot de bewering, dat in dat land alle ondernemingen tot mislukking gedoemd zijn, groote mogelijkheden bestaan. Dit geldt in de eerste plaats voor de goudindustrie, waarvan het product ten allen tijde op de wereldmarkt gereede afzet vindt. Evenals het product der balata-industrie, dat door de invoering van de draadlooze telegrafie zijn marktwaarde verloren heeft, wordt goud in het binnenland van Suriname verspreid aangetroffen. Door de verkenningen, gedurende meer dan twintig jaren ten behoeve van de balata-industrie uitgevoerd, is komen vast te staan, dat in het zuiden der kolonie overal goede aanwijzingen voor goudvoorraden worden aangetroffen. Het is niet uitgesloten, dat in de gebieden, welke de gouddelvers de derde goudzône noemen, welke nooit door de goudindustrie werden aangesproken, de voorraden worden gevonden, die in Suriname tot een geregeld mijnbedrijf kunnen leiden. Slechts door de invoering van vrij onderzoek in deze gebieden en door dit onderzoek niet aan tijdsbepalingen te onderwerpen zal het mogelijk zijn zonder kostbare proefnemingen de bodemschatten ten behoeve der Surinaamsche huishouding dienstbaar te maken. Aan dit onderzoek moeten ontginnings- en voorkeursrechten verbonden zijn, waardoor gevonden goudplaatsen in rechtmatig bezit van den vinder komen. Een aanduiding van de wijze, waarop dit kan geschieden, is reeds in de wijziging der wet ten behoeve der werkelooze gouddelvers in 1931 gegeven. Bij deze wijziging werd ook de retributie, die vroeger zeven centen per gram bedroeg, op vier centen teruggebracht. Deze kan gevoegelijk op tien à vijftien centen vastgesteld worden. Hierdoor zal het verlies, dat door de vrije uitgifte van het land geleden wordt, ruimschoots vergoed worden.

Zooals hiervóór reeds werd opgemerkt, vereischt het gouddelven eenig kapitaal. De Surinamers, die gaarne het bosch zouden willen intrekken, bezitten echter niets. Een gedeelte dezer economisch zwakken tracht als onderhuurders op de concessies der 
maatschappijen, die vroeger het goud delven, machinaal hebben gedreven, een bestaan te vinden. Zoodoende is op een dezer concessies langs den spoorweg te De Jong Zuid een dorpje van gouddelvers ontstaan. De kansen zijn echter aldaar niet groot, het tertein der goudhoudende formaties is te klein, en buitendien worden dit terrein en de omtrekken reeds sedert meer dan vijftig jaren afgeloopen. Op andere groote concessies is de toestand ongeveer dezelfde. De onderhuurders behoeven geen concessiesrechten te betalen en zijn niet aan bepaalde plaatsen gebonden; de werkplaatsen worden geacht binnen de verleende concessie te liggen. Als tegenprestatie moeten de onderhuurders het gevonden goud tegen een overeengekomen prijs aan de houders der concessies inleveren. Dit onderhuurstelsel kan tot grondslag van den nieuwen bedrijfsvorm dienen, welke in het algemeen, en in het zuiden der kolonie in het bijzonder, ingevoerd behoort te worden.

Een of meer kapitaalkrachtige ondernemingen moeten onder nader met het bestuur van Suriname overeen te komen voorwaarden groote oppervlakten goud voor de uitoefening van het goudbedrijf in bezit nemen. In het centrum van formaties, die goede aanwijzingen van goudhoudenden grond hebben opgeleverd, worden magazijnen opgericht, die de gouddelvers van levensmiddelen en andere benoodigdheden, zooals gereedschappen, kleeding, enz. voorzien. Het aanleggen in de onmiddellijke nabijheid der magazijnen van vestigingen en het verbouwen van voedselgewassen moet bevorderd worden. Hierdoor worden kleine bevolkingscentra in het leven geroepen, waar de gouddelver ontspanning vindt, en zoowel de onderlinge bijstand als ook het toezicht der onderneming gebaat wordt. De ter plaatse aanwezige magazijnmeester neemt het gevonden goud ten behoeve der onderneming in ontvangst. Overigens hebben de verrekeningen met de gouddelvers plaats, zooals hiervoor ten aanzien van de balata-industrie werd vermeld.

De onkosten van het bedrijf zullen aanmerkelijk geringer zijn dan ze bij deze laatste industrie zijn geweest, omdat de afvoer van het product zoo goed als geen kosten met zich brengt. Ook door de meer permanente inrichting van het bedrijf ten opzichte van de gouddelvers wordt het risico belangrijk verminderd. De met dezen te sluiten overeenkomsten behoeven hier niet besproken te worden.

Tenslotte wordt nog vermeld, dat de beide groote rivieren, de Suriname en de Saramacca, aan welker bovenloopen talrijke aanwijzingen van goudhoudende formaties aangetroffen worden, in 
het bijzonder ten opzichte van het vervoer gunstig gelegen zijn. Aldaar wonen de Boschnegers, die thans gedwongen zijn in de vrachtvaart bij het goudbedrijf van het naburige Cayenne verdiensten te zoeken.

Evenals dit in den regel het geval is, wanneer voorstellen worden gedaan, die tot de economische ontwikkeling der kolonie kunnen bijdragen, welke echter naar de meening van het bestuur of de hier te lande vertoevende deskundigen niet uitvoerbaar worden geacht, zal ook het hier gedane voorstel bestreden worden. Dit zal begrijpelijk zijn, wanneer men bedenkt, dat bij het in overweging nemen dezer voorstellen de gedurende vele jaren plaats gehad hebbende tekortkomingen van tal van verantwoordelijke personen aan het licht zouden komen. Daarom wordt objectief onderzoek altijd geweerd. Kan men zich daartegen echter niet verzetten, dan worden de resultaten genegeerd, zooals dit ten aanzien van de Lawa-exploratie heeft plaats gehad, ten opzichte van het onderzoek van het Suriname Studie Syndicaat en het onderzoek van Pyttersen en van dr. Pfeiffer is geschied.

Tenslotte nemen wij de eindconclusie van een artikel, verschenen in de N.R.C., avondblad van 23 Mei 1933, over, waarin hetzelfde voorstel werd besproken, dat in dit opstel bepleit is. $\mathrm{Zij}$ luidt: „Aan de invoering van dezen bedrijfsvorm bij de goudontginning, voor welken groote kapitaalaanleg geen vereischte is, en bij welken de door het gouvernement te heffen rechten meer het product dan den grond moesten belasten, zullen de volgende voordeelen verbonden zijn:

$1^{\circ}$. De tot nu toe angstvallig afgesloten gebieden zullen geëxploreerd worden. Behalve van goud| worden in deze landstreken tal van aanwijzingen van andere metalen en mineralen gevonden.

$2^{\circ}$. Paramaribo zal van een groot aantal menschen ontlast worden, welke aldaar geen bestaan kunnen vinden en voor de samenleving een voortdurend gevaar opleveren.

$3^{\circ}$. De ontvangsten der koloniale kas zullen eene niet onbelangrijke vermeerdering ondergaan.

Buitengewone omstandigheden eischen het nemen van buitengewone maatregelen en hoogere krachtsinspanning.

Het is te hopen, dat het besef van deze waarheid bij het bestuur der kolonie doordringt en de aangelegenheid als nog in studie en overweging wordt genomen."

Hilversum, Kerstmis 1939. 